\title{
SPECIATION FEATURES OF GOLD IN ORES AND MINERALS OF THE NATALKINSKOE DEPOSIT (NORTH-EAST RUSSIA)
}

\section{R.G. Kravtsova $\odot$, A.S. Makshakov ${ }^{\circledR}$, V.L. Tauson $₫$, 0.Yu. Belozerova $₫$, V.V. Tatarinov $₫$}

Vinogradov Institute of Geochemistry, Siberian Branch of the Russian Academy of Sciences, 1a Favorsky St, Irkutsk 664033, Russia

ABSTRACT. The distribution and speciation features of gold in ores and minerals of the Natalkinskoe gold deposit (North-East Russia) are studied using light microscopy (LM), scanning electron microscopy with energy dispersive X-ray spectrometry (SEM-EDX), X-ray electron probe microanalysis (EPMA), "phase" chemical analysis with atomic absorption spectrometry (PCA-AAS) and atomic absorption spectrometry with analytical data selections for single crystals (AAS-ADSSC). The vein and streaky-vein ores are high-grade ores, whereas veinlet-disseminated ores are less rich and disseminated ores are poor in gold. Up to $85 \%$ of the gold in the ores is in a free native state, associated with quartz and sulfide minerals. LM, SEM-EDX and EPMA reveal that the predominant gold grains are 0.01 to $2.00 \mathrm{~mm}$ in size and at a fineness of 720 to $900 \%$. The finely dispersed and submicron elemental gold particles ( $\left.\mathrm{Au}^{0}\right)$ amounted to $20 \%$ and are mainly enclosed into arsenopyrite and pyrite. According to PCA-AAS data, the highest Au concentrations (up to $1383 \mathrm{ppm}$ ) are recorded in arsenopyrite; lower contents are typical of pyrite (up to $158.2 \mathrm{ppm}$ ). In these sulfides, two non-mineral species of "invisible" Au are the structurally bound and surface-bound species recognized by AAS-ADSSC. The structural $\mathrm{Au}$ is included in the mineral structure. The surface-bounded Au prevails and is confined to nano-sized, non-autonomous phases (NAPs) on the sulfide surface. In common with "invisible" Au, the micro-sized particles of native gold are often observed on the surface and within the surface layers of sulfide crystals. This is consistent with the model of post-growth transformations of nano-sized NAPs, resulting in the formation of nano and micro-sized $\mathrm{Au}^{0}$ particles. It is expected that the major part of gold contained in arsenopyrite and pyrite as finely dispersed and submicron particles, as well as the surface-bound gold in NAPs, can be won with modified current schemes of gold concentration, which enhances the value of the gold ore mining.

KEYWORDS: North-East Russia; Natalkinskoe deposit; gold; ores; arsenopyrite; pyrite; distribution; speciation

FUNDING: The study was performed by the governmental assignment in terms of project 0284-2021-0002, with RFBR funding (project 20-05-00142) and using scientific equipment of the Shared Research Facilities "Isotopic-geochemical investigations" IGC SB RAS (Irkutsk, Russia) and the Shared Research Facilities "Ultramicroanalysis" LIN SB RAS (Irkutsk, Russia).

\section{SHORT COMMUNICATION}

Correspondence: Artem S. Makshakov, artem_m@mail.ru
Received: December 3, 2021

Revised: December 22, 2021

Accepted: December 30, 2021

FOR CITATION: Kravtsova R.G., Makshakov A.S., Tauson V.L., Belozerova O.Yu., Tatarinov V.V., 2022. Speciation Features of Gold in Ores and Minerals of the Natalkinskoe Deposit (North East Russia). Geodynamics \& Tectonophysics 13 (2s), 0595. doi:10.5800/GT-202213-2s-0595 


\title{
ФОРМЫ НАХОЖДЕНИЯ ЗОЛОТА В РУДАХ И МИНЕРАЛАХ НАТАЛКИНСКОГО МЕСТОРОЖДЕНИЯ (СЕВЕРО-ВОСТОК РОССИИ)
}

\author{
Р.Г. Кравцова, А.С. Макшаков, В.Л. Таусон, О.Ю. Белозерова, В.В. Татаринов
}

Институт геохимии им. А.П. Виноградова СО РАН, 664033, Иркутск, ул. Фаворского, 1а, Россия

\begin{abstract}
АННОТАЦИЯ. С помощью оптической микроскопии (ОМ), сканирующей электронной микроскопии с энергодисперсионной спектрометрией (СЭМ-ЭДС), рентгеноспектрального микроанализа (РСМА), фазового химического анализа на основе атомно-абсорбционной спектрометрии (ФХА-ААС) и метода статистических выборок аналитических данных для монокристаллов с применением ААС (СВАДМ-АAC) проведено изучение особенностей распределения и форм нахождения $(\Phi Н)$ Аи в рудах и минералах Наталкинского золоторудного месторождения (северовосток России). К наиболее «богатым» здесь относят жильные и прожилково-жильные руды, к менее «богатым»прожилково-вкрапленные, к «бедным»- вкрапленные. До 80-85 \% Аи в руде находится в свободном самородном состоянии в ассоциации с кварцем и сульфидными минералами. По данным ОМ, СЭМ-ЭДС и РСМА преобладают золотины размером 0.01-2.00 мм и пробностью 720-900 \%о. До 15-20 \% приходится на долю тонкодисперсных и субмикронных частиц элементного золота $\left(\mathrm{Au}^{0}\right)$, большая часть которых заключена в арсенопирите и пирите. По данным ФХА-ААС самые высокие концентрации Аи отмечены в арсенопирите (до 1383 г/т), менее высокие - в пирите (до 158.2 г/т). С помощью метода СВАДМ-ААС в этих сульфидах установлены две неминеральные ФН «невидимого» $\mathrm{Au}$ - структурная и поверхностно-связанная. Первая входит в структуру минералов, вторая, преобладающая, приурочена к наноразмерным неавтономным фазам (НФ) на их поверхности. Наряду с «невидимым» Аи часто на поверхности и в поверхностном слое сульфидов развиты микровключения самородного $\mathrm{Au}$, что согласуется с моделью постростовых преобразований наноразмерных НФ, приводящих к возникновению нано- и микрочастиц $\mathrm{Au}^{0}$. Предполагается, что большую часть золота, находящегося в сульфидах в виде тонкодисперсных и субмикронных частиц, а также поверхностно-связанного золота в НФ можно извлечь при доработке уже имеющихся схем обогащения, что повышает ценность добываемого сырья и значительно увеличивает перспективы месторождения.
\end{abstract}

КЛЮЧЕВЫЕ СЛОВА: северо-восток России; Наталкинское месторождение; золото; руда; арсенопирит; пирит; распределение; форма нахождения

ФИНАНСИРОВАНИЕ: Исследование проведено в рамках выполнения государственного задания по проекту № 0284-2021-0002 и при финансовой поддержке РФФИ (проект № 20-05-00142) с использованием научного оборудования ЦКП «Изотопно-геохимические исследования» ИГХ СО РАН (г. Иркутск) и ЦКП «Ультрамикроанализ» ЛИН СО РАН (г. Иркутск).

\section{1. ВВЕДЕНИЕ}

Территория северо-востока России известна как крупнейшая золотоносная провинция. По концентрации месторождений золота, многие из которых не имеют аналогов ни в России, ни за рубежом, она уникальна [Palymsky et al., 2006; Mikhailov et al., 2007]. Наталкинское золотокварцевое (Au-Q) месторождение-гигант является одним из самых ярких примеров [Goncharov et al., 2002; Goryachev et al., 2008]. При изучении вещественного состава руд этого месторождения основное внимание уделялось собственно самородному $\mathrm{Au}$, меньшее - проблеме исследования тонкодисперсного ( $<10$ мкм) и так называемого «невидимого» Au. B pyдах орогенных Au-Q месторождений такое Au обычно составляет до 20-25 \% и связано с сульфидами [Firsov, 1985; Goncharov et al., 2002]. В рудах Наталкинского месторождения это арсенопирит и пирит. Потери Аu при извлечении из сульфидных концентратов неизбежны и зачастую значительны. По данным Н.И. Горячкина с соавторами [Goryachkin et al., 1999], на этом месторождении при обогащении золоторудного сырья по принятой на сегодняшний день схеме потери этого металла в хвостах сорбции сульфидных концентратов составляют до 20-30 \% от всего Au (8.03 г/т) в этом концентрате. Даже для таких технологически относительно простых месторождений, как Наталкинское, эти потери являются весьма чувствительными. Золото, теряемое при переработке сырья вместе с сульфидной составляюеей, в основном «невидимое» и тонкодисперсное. Руды, содержащие такое $\mathrm{Au}$, считаются «упорными», требующими применения специальных технологических схем. Проведение исследований по изучению форм нахождения $(\Phi \mathrm{H})$ такого Аи является важным не только для изучения генезиса золоторудных месторождений. Как известно, выяснение природы потерь «упорного» Аu из сульфидных концентратов и оценка возможности использования полученных результатов на практике на сегодняшний день не менее актуальны и крайне востребованы.

\section{2. ОБЪЕКТЫ ИССЛЕДОВАНИЯ}

Наталкинское $\mathrm{Au}-\mathrm{Q}$ месторождение, руды и минералы которого являются объектами наших исследований, относится к орогенной $\mathrm{Au}-\mathrm{Q}$ рудной формации 
малосульфидного типа, отличается сложным, длительным развитием и, по мнению большинства исследователей, метаморфогенно-магматогенным генезисом [Goncharov et al., 2002].

Рудная залежь в окварцованных позднепермских осадочных толщах, в основном в диамиктитах, алевролитах и сланцах, представляет собой меньшую часть минерализованной зоны [Grigorov et al., 2007], состоящей из кварцевых жил, прожилков и вкрапленной сульфидной минерализации. К наиболее «богатым» можно отнести жильные и прожилково-жильные руды, к менее «богатым» - прожилково-вкрапленные, к «бедным» - вкрапленные. В первых трех типах наиболее распространенными рудными минералами являются арсенопирит и пирит, реже встречаются галенит, халькопирит, сфалерит, пирротин, рутил, самородное золото. Вкрапленные руды не представляют в настоящее время практического интереса. Основной рудный минерал в них - пирит. Арсенопирит встречается редко.

Для изучения ФН Au в рудах и сульфидных минералах, арсенопирите и пирите, по разным участкам и горизонтам месторождения было отобрано более 300 геохимических проб и около 100 крупнообъемных минералого-геохимических (штуфных) проб. Все пробы были проанализированы на Au.

\section{3. МЕТОДЫ ИССЛЕДОВАНИЯ}

Для определения валовых содержаний $\mathrm{Au}$ в отобранных нами геохимических и штуфных пробах был использован метод атомно-абсорбционной спектрометрии (AАC), основанный на извлечении Аu из растворов путем экстракции органическими сульфидами с замерами на приборе Perkin-Elmer M503 (США) с графитовой печью-атомизатором [Gold Determination..., 2016]. Предел обнаружения $\mathrm{Au}$ данным методом - 0.0002 г/т.

Наряду с оптической микроскопией (OM) при исследовании вещественного состава руд были использованы методы сканирующей электронной микроскопии, сопряженной с энергодисперсионной спектрометрией (СЭМ-ЭДС), и рентгеноспектрального микрозондового анализа (РСМА). СЭМ-ЭДС исследования проводились на растровом электронном микроскопе FEI Company Quanta 200 с энергодисперсионной приставкой EDAX (США), PCMA - на микроанализаторе JXA-8200 Super Probe (JEOL Ltd., Япония) [Pavlova et al., 2000; Pavlova, 2014; Finkelshtein et al., 2018].

Для изучения общего содержания Au в монофракциях арсенопирита и пирита был использован фазовый химический анализ на основе ААС (ФХА-ААС). Истертый материал разлагали царской водкой. Затем он обрабатывался концентрированной $\mathrm{HCl}$ с упариванием досуха для удаления остатков азотной кислоты и перевода солей в хлоридную форму. После охлаждения пробы доводились до определенного объема фоном - раствором $2 \mathrm{M} \mathrm{HCl}$ для съемки методом AAC на приборе PerkinElmer M503. Предел обнаружения Au - 0.0002 г/т.

Изучение ФН так называемого «невидимого» $\mathrm{Au}$ в арсенопирите и пирите проводилось по технологии статистических выборок аналитических данных для монокристаллов с применением ААС (СВАДМ-ААС). Метод подробно описан в публикациях [Tauson et al., 2002; Tauson, Lustenberg, 2008]. Он основан на статистической обработке аналитических данных для большого числа отдельных кристаллов пробы с целью разделения структурной и поверхностно-связанной ФН элемента. Изучено более 400 кристаллов арсенопирита и 250 - пирита. Определение Аu в растворах, полученных путем кислотного разложения кристаллов, проводилось непосредственно из раствора после создания необходимого состава среды и введения стабилизирующей добавки $\mathrm{NaCl}$. Измерения проводились методом AAC с электротермической атомизацией на приборе Perkin-Elmer M503. Точность определения составляла $\pm 12 \%$, предел обнаружения $\mathrm{Au}-0.0003$ г/т.

\section{4. РЕЗУЛЬТАТЫ И ИХ ОБСУЖДЕНИЕ}

По данным AАС, для жильных и прожилково-жильных руд характерны высокие средние содержания $\mathrm{Au}$ (г/т) - 29.2 при интервале значений от 1.5 до 115.4. Для прожилково-вкрапленных руд обычны относительно низкие содержания $\mathrm{Au}(г / \mathrm{T})$, в среднем 2.7, при интервале значений от 0.5 до 16.9. Для вкрапленных руд средние содержания $\mathrm{Au}(\mathrm{r} / \mathrm{T})$ составляют 0.35 при интервале значений 0.02-1.94.

В жильных, прожилково-жильных и прожилкововкрапленных рудах преобладает Аи в свободном состоянии в ассоциации с нерудными и сульфидными минералами. Основные носители $\mathrm{Au}$ - нерудные минералы, в основном кварц, основные концентраторы - сульфидные минералы, такие как арсенопирит и пирит [Goryachkin et al., 1999; Goncharov et al., 2002]. Для вкрапленных руд и концентраторами, и носителями Аи является в основном пирит. Самородное $\mathrm{Au}$ присутствует только в виде единичных тонкодисперсных включений размером 1 мкм и менее.

\section{1. Самородное золото}

До 80-85 \% золота в руде находится в свободном самородном состоянии в ассоциации в основном с жильным кварцем и сульфидами (рис. 1). В изученной выборке преобладают золотины размером 0.01-2.00 мм, пробностью от 730 до 860 \%о. Ассоциация самородное золото - арсенопирит является наиболее типичной (рис. 1, в, г, д, е). До 15-20 \% приходится на долю тонко- и ультрадисперсного Au (<10 мкм), большая часть которого заключена в арсенопирите и пирите (рис. 2). Обычно Au выполняет пространство между кристаллами или дефекты в них. Пробность включений 720$900 \%$ (см. рис. 1, д, е).

По данным СЭМ-ЭДС и РСМА, большая часть рудных элементов находится в самородном золоте в виде микровключений собственных минералов. Это арсенопирит, рутил, халькопирит, галенит, сфалерит и сульфосоли серебра. Качественный и количественный состав примесных элементов крайне беден. Кроме Ag (1028 мас. \%), в виде примеси в золотинах присутствуют 

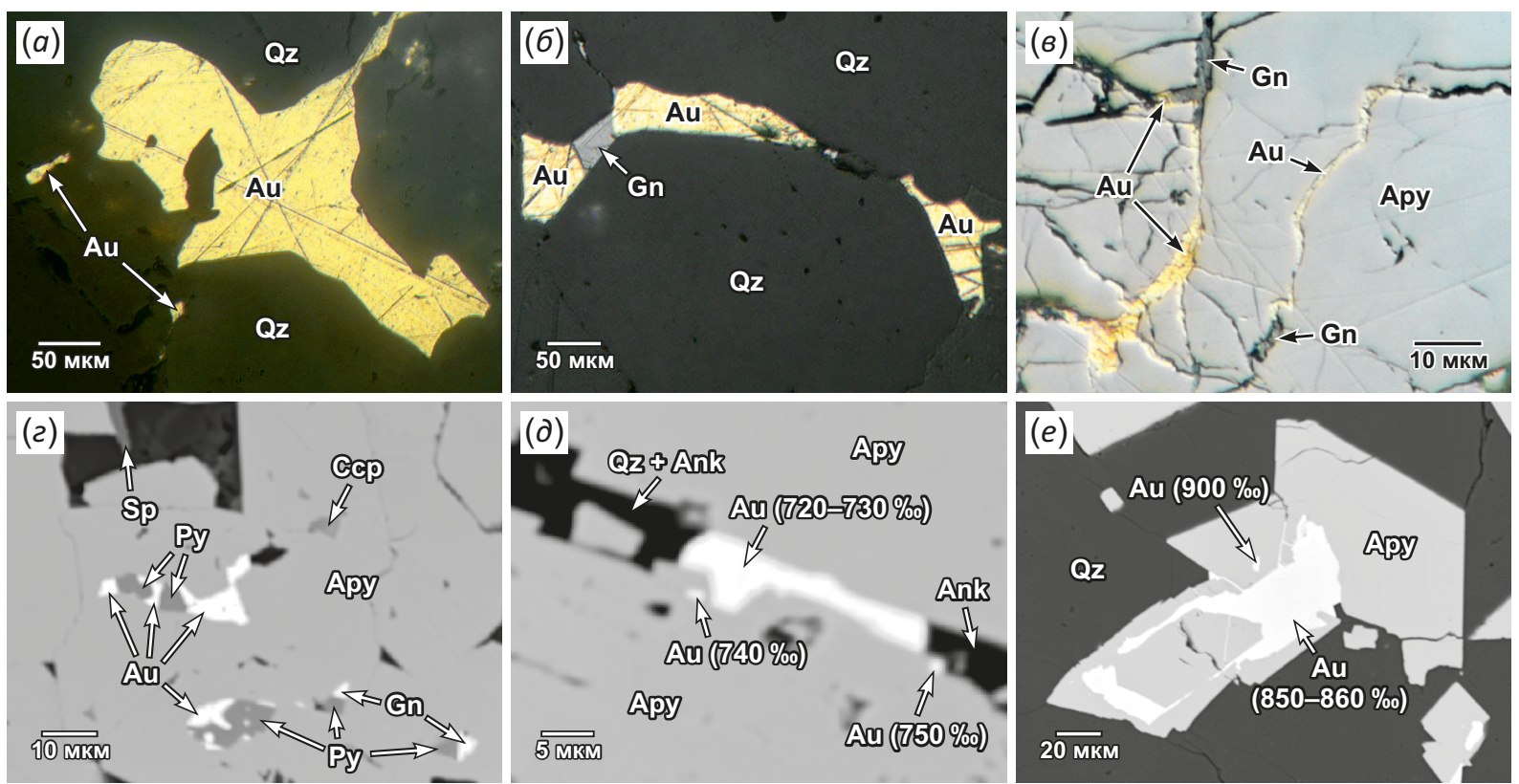

Рис. 1. Минеральные ассоциации самородного золота.

$(a-8)$ - золото с жильным кварцем $(a)$, с кварцем и галенитом (б), с арсенопиритом и галенитом $(8) ;(2)-$ включения золота, пирита, сфалерита и халькопирита в арсенопирите; $(\partial)$ - фрагмент кристалла арсенопирита с микротрещинами и кавернами, заполненными кварцем, анкеритом и золотом (здесь и на фрагменте (e) в скобках указана пробность золота); $(e)-$ золото в ассоциации с арсенопиритом в кварце. Изображения даны: $(a-8)$ - в отраженном свете (оптический микроскоп), $(2-e)-$ в обратно-рассеянных электронах: (2) - PCMA, (d, e) - СЭМ-ЭДС. Здесь и на рис. 2: Au - золото, Qz - кварц, Gn - галенит, Ару - арсенопирит, Sp - сфалерит, Ру - пирит, Сср - халькопирит, Ank - анкерит.

Fig. 1. Mineral associations of native gold.

$(a-b)$ - gold with vein quartz $(a)$, with quartz and galena (6), with arsenopyrite and galena $(b)$; $(2)$ - inclusions of gold, pyrite, sphalerite and chalcopyrite in arsenopyrite; $(\partial)$ - fragment of arsenopyrite crystal with microcracks and cavities filled with quartz, ankerite and gold (here and in fragment $(e)$, gold fineness is indicated in parentheses); $(e)$ - gold in association with arsenopyrite in quartz. Images are given: $(a-8)$ - in reflected light (light microscope), (2-e) - in backscattered electrons: (2) - EPMA; $(\partial, e)-$ SEM-EDX. Here and in Fig. 2: $\mathrm{Au}$ - gold, Qz - quartz, Gn - galena, Apy - arsenopyrite, Sp - sphalerite, Py - pyrite, Ccp - chalcopyrite, Ank - ankerite.
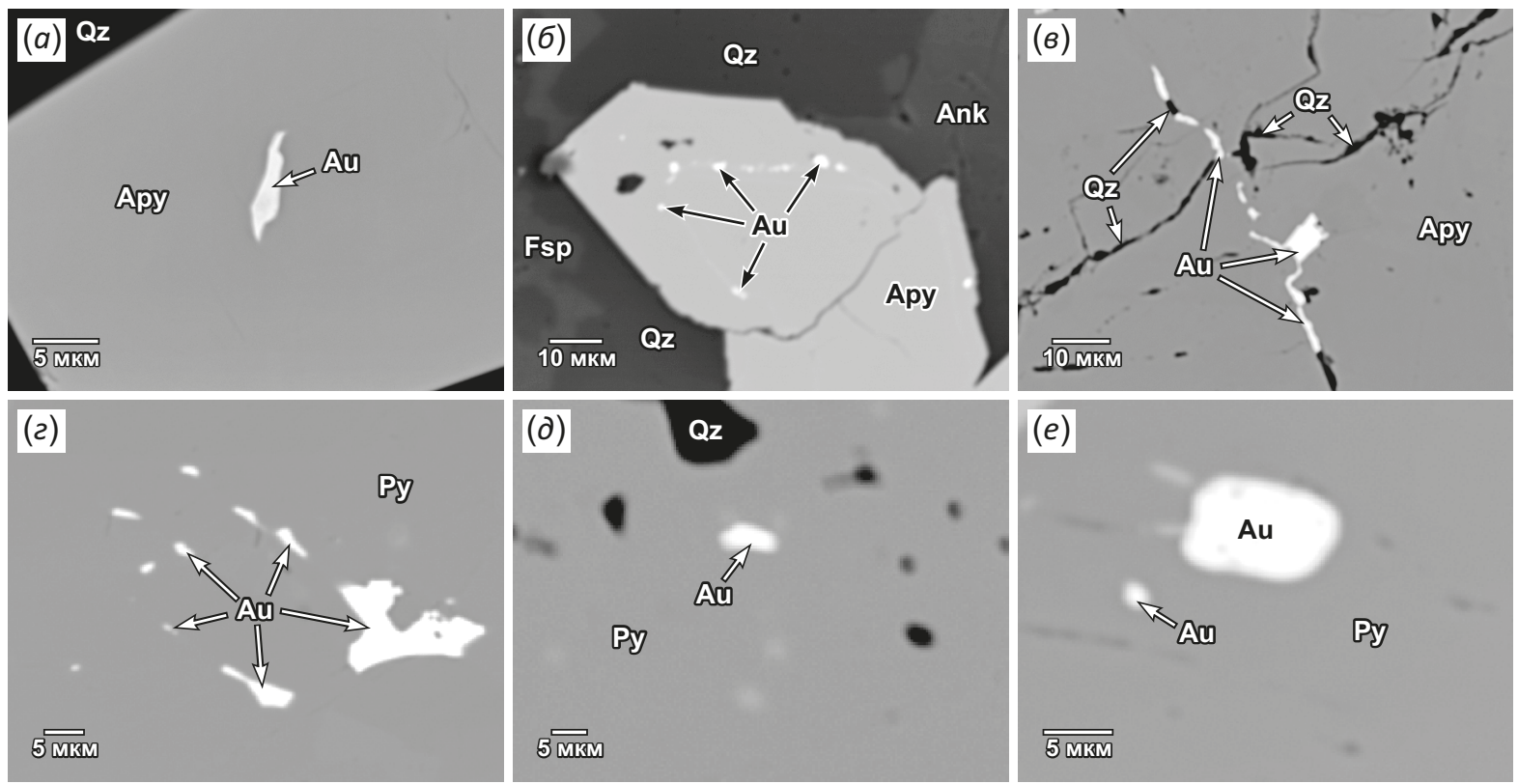

Рис. 2. Микро- и тонкодисперсные включения золота в арсенопирите и пирите: $(a)$ - в кристалле арсенопирита; (б) - по зонам роста кристалла арсенопирита; ( 8 ) - по трещинкам в арсенопирите, заполненным кварцем; $(2-e)$ - в пирите. Изображения даны в обратно-рассеянных электронах (PCMA). Fsp - калиевый полевой шпат.

Fig. 2. Micro- and finely dispersed inclusions of gold in arsenopyrite and pyrite: $(a)$ - in the arsenopyrite crystal; (б) - in the growth zones of the arsenopyrite crystal; $(B)$ - in the cracks of the arsenopyrite filled with quartz; $(2-e)$ - in pyrite. Images are given in backscattered electrons (EPMA). Fsp - K-feldspar. 
(в мас. \%) Se (0.46-2.57) и Те (0.20-0.26), реже встречаются $\mathrm{Bi}(0.32-1.02)$ и $\mathrm{Hg}(0.23-0.87)$, еще реже - Cu (0.28$0.86)$ и As (0.5-0.9). Возможно, эти элементы, находящиеся в золотинах в «невидимом» состоянии, в значительной своей части тоже представлены собственно минеральными формами, только ультрадисперсными и наноразмерными (<0.1 мкм).

\section{2. «Невидимое» золото}

С помощью метода СВАДМ-ААС были изучены уровни концентрирования и ФН так называемого «невидимого» Au в главных сульфидных минералах - арсенопиритах и пиритах. Для этого из выделенных разноразмерных мономинеральных фракций (от 0.14 до 2.00 мм) отбирались кристаллы только с хорошо выраженной морфологической формой, так называемые «идеальные» кристаллы, не содержащие видимых включений. Кристаллы отбирались из мономинеральных фракций арсенопирита и пирита, предварительно прошедших ФХА-АAC на Аu. Полученные данные показали, что не только арсенопирит [Kravtsova et al., 2015], но и пирит Наталкинского месторождения является концентратором Au. По данным ФХА-ААС, самые высокие концентрации Аu отмечены в монофракциях сульфидов из жильных руд: в арсенопирите - до 1383 г/т, в пирите - до 158 г/т. Самые низкие концентрации установлены в монофракциях сульфидов из вкрапленных руд: в арсенопирите - до 3.8 г/т, в пирите - до 3.4 г/т. По данным предыдущих исследователей, максимальные содержания Au в пирите из вкрапленных руд составили 2.2 г/т [Goncharov et al., 2002]. Результаты ФХА-AAC и данные СВАДМ-ААС приведены в табл. 1.

Кроме тонкодисперсных и субмикронных частиц элементного золота $\left(\mathrm{Au}^{0}\right)$, в арсенопирите и пирите были установлены две неминеральные ФН «невидимого» равномерно распределенного $\mathrm{Au}$ - структурная и поверхностно-связанная. Первая соответствует химически связанному элементу в структуре минерала, вторая, преобладающая, входит в состав наноразмерных неавтономных фаз (НФ), существующих в очень тонком поверхностном слое кристалла ( 100-500 нм) (табл. 1). Проведенное ранее изучение поверхностного слоя кристаллов методами СЭМ-ЭДС и ЛА-ИСП-МС подтвердило присутствие Au [Kravtsova et al., 2015, 2020a, 2020 b]. Установлено, что наряду с «невидимым» Аu часто на поверхности и в поверхностном слое арсенопирита и пирита развиты его микронные включения. Предполагается, что при постростовых преобразованиях

Таблица 1. Содержание золота, в том числе «невидимых» форм, в монофракциях арсенопирита и пирита из руд Наталкинского месторождения

Table 1. Gold content, including "invisible" forms, in monofractions of arsenopyrite and pyrite from ores of the Natalkinskoe deposit

\begin{tabular}{|c|c|c|c|c|c|c|}
\hline \multirow{2}{*}{ № пробы } & \multirow{2}{*}{ Тип руд } & \multicolumn{4}{|c|}{$\mathrm{Au}, \Gamma / \mathrm{T}$} & \multirow{2}{*}{$\mathrm{C}_{\text {пов. }} /\left(\mathrm{C}_{\text {стр. }}+\mathrm{C}_{\text {пов. }}\right), \%$} \\
\hline & & $\mathrm{C}_{1}$ & $\mathrm{C}_{2}$ & $\mathrm{C}_{\text {стр. }}$ & $\mathrm{C}_{\text {пов. }}$ & \\
\hline \multicolumn{7}{|c|}{ Арсенопирит } \\
\hline M-161/10 & \multirow{2}{*}{ жильный } & $19.1-1383(626.1)$ & $2.3-20.1(18.9)$ & 0.07 & 6.12 & 98.9 \\
\hline $\mathrm{M}-129 / 10$ & & $46.5-141(93.8)$ & $24.1-141(55.9)$ & 6.77 & 30.43 & 81.8 \\
\hline $\mathrm{M}-131 / 10$ & \multirow{3}{*}{ прожилково-жильный } & $6.2-84.9(32.7)$ & $1.9-146(62.6)$ & 0.01 & 17.05 & 99.9 \\
\hline$\Gamma-9 / 13$ & & $11.3-24.0(15.4)$ & $1.9-59.3(14.4)$ & 0.21 & 5.53 & 96.3 \\
\hline ТПМ-1/1 & & $9.7-53.3(26.3)$ & $31.5-124(125)$ & 5.01 & 54.59 & 91.6 \\
\hline Нат-10 & \multirow{2}{*}{ прожилково-вкрапленный } & $1.4-7.4(3.8)$ & $1.9-8.2(5.1)$ & 1.21 & 1.91 & 61.3 \\
\hline Юв-3/13 & & $8.1-37.0(23.2)$ & $0.8-5.9(2.2)$ & 0.12 & 1.30 & 91.5 \\
\hline ВК-2/10 & вкрапленный & $2.5-3.8(3.1)$ & $1.0-3.2(2.5)$ & 0.04 & 1.21 & 96.8 \\
\hline \multicolumn{7}{|c|}{ Пирит } \\
\hline $\mathrm{M}-161 / 10$ & жильный & $15.3-158.2(65.4)$ & $6.9-47.1(36.3)$ & 0.35 & 17.22 & 98.0 \\
\hline ТПМ-1/1 & \multirow{2}{*}{ прожилково-жильный } & $1.9-17.9(8.5)$ & $1.8-7.9(6.2)$ & 0.32 & 3.40 & 91.4 \\
\hline ТПМ-1/2 & & $1.3-16.5(7.4)$ & $1.7-7.6(5.9)$ & 0.33 & 3.10 & 90.4 \\
\hline Нат-10 & \multirow{2}{*}{ прожилково-вкрапленный } & $1.2-4.6(2.6)$ & $3.1-8.5(5.3)$ & 1.80 & 2.71 & 60.0 \\
\hline Юв-3/13 & & $0.8-6.6(4.6)$ & $1.0-6.0(2.7)$ & 0.29 & 1.41 & 82.8 \\
\hline ВК-2/10 & вкрапленный & $2.1-3.4(2.9)$ & $2.0-3.9(2.8)$ & 0.05 & 1.10 & 95.7 \\
\hline
\end{tabular}

Примечание. $\mathrm{C}_{1}$ - интервал содержаний $\mathrm{Au}$ в мономинеральных фракциях арсенопирита и пирита, состоящих из агрегатов этих минералов, кристаллов разных морфологических форм и их комбинаций (в скобках даны средние содержания); $\mathrm{C}_{2}-$ интервал содержаний Аи в размерных фракциях, состоящих из «идеальных» кристаллов арсенопирита и пирита с хорошо выраженной морфологической формой (в скобках даны средние содержания); $\mathrm{C}_{\text {стр. }}$ - содержание структурной формы $\mathrm{Au} ; \mathrm{C}_{\text {пов. }}$ - среднее содержание поверхностно-связанной формы Аи. $\mathrm{C}_{1}-$ данные ФХА-ААС; $\mathrm{C}_{2}, \mathrm{C}_{\text {стр }}$ и $\mathrm{C}_{\text {пов }}$ - данные СВАДМ-ААС.

Note. $\mathrm{C}_{1}$ is the range of $\mathrm{Au}$ contents in monomineral fractions of arsenopyrite and pyrite, represented by aggregates, crystals of different morphological forms and their combinations (the average contents are given in parentheses); $\mathrm{C}_{2}$ is the range of Au contents in the size fractions consisting of "ideal" arsenopyrite and pyrite crystals with a well-defined morphological form (the average contents are given in parentheses); $\mathrm{C}_{\text {str }}$ is the content of the $\mathrm{Au}$ structural form; $\mathrm{C}_{\text {sur }}$ is the average content of the Au surficially bound form. $\mathrm{C}_{1}$ are PCA-AAS data; $\mathrm{C}_{2}, \mathrm{C}_{\text {str }}$ and $\mathrm{C}_{\text {sur }}$ are AAS-ADSSC data. 
наноразмерных НФ могут возникать микро- и наночастицы металлического $\mathrm{Au}^{0}$. Появление микроминеральных форм $\mathrm{Au}^{0}$ в кристаллах сульфидов и в их поверхностных слоях говорит в пользу предположения о частичной трансформации и направленной агрегации Au-содержащих наноразмерных НФ. Поверхность является местом выхода дислокаций, с которыми связаны повышенные концентрации микроэлементов, в том числе и Au. Это подтверждается исследованиями природно-деформированного пирита с помощью современных методов микроанализа - дифракции обратно-рассеянных электронов, ЛА-ИСП-МС и атомно-зондовой томографии [Dubosq et al., 2019]. В результате происходит образование частиц $\mathrm{Au}^{0}$, от наноразмерных до субмикронных [Tauson et al., 2014, 2018]. Это делает возможным извлечение такого Au при обогащении руд, что может значительно повысить качество и ценность добываемого сырья.

\section{5. ЗАКЛЮЧЕНИЕ}

Основными носителями Аи являются нерудные минералы. По данным ААС содержание Аu в промышленных рудах Наталкинского месторождения изменяется от 0.5 до 115.4 г/т. По результатам РСМА и СЭМ-ЭДС пробность частиц самородного Аи размером 0.01-2.00 мм составляет 730-860\%, размером $<0.01$ мм - 720-900\%о. Состав примесных элементов беден. Кроме Ag, часто присутствуют Se и Te, реже встречаются Bi и $\mathrm{Hg}$, еще реже - Cu и As. Предполагается, что большая часть этих элементов представлена собственно минеральными формами в виде наноразмерных частиц.

Основными концентраторами Аи являются арсенопирит и пирит. По данным ФХА-ААС самые высокие концентрации Аu отмечены в монофракциях арсенопирита - до 1383 г/т, менее высокие - пирита, до 158.2 г/т. Кроме тонкодисперсных и субмикронных частиц элементного золота $\left(\mathrm{Au}^{0}\right)$, в арсенопирите и пирите методом СВАДМ-ААС были установлены две его неминеральные ФН - структурная и поверхностносвязанная. Первая входит в структуру минерала, вторая, преобладающая, в состав наноразмерных НФ на его поверхности.

Наряду с «невидимым» $\mathrm{Au}$, часто на поверхности и в поверхностном слое сульфидов развиты микронные включения самородного Au. Это согласуется с моделью постростовых преобразований наноразмерных НФ, приводящих к возникновению нано- и субмикронных частиц $\mathrm{Au}^{0}$. Появление таких форм $\mathrm{Au}$ в кристаллах сульфидов говорит в пользу предположения о частичной трансформации и направленной агрегации $\mathrm{Au}$-содержащих НФ.

Предполагается, что большую часть находящегося в сульфидах «невидимого» Аu можно уловить при доработке уже действующих технологических схем обогащения. В перспективе это открывает возможность вовлечения в разработку на месторождении зон вкрапленных руд. С учетом объемов занимаемых ими площадей в будущем они могут стать одним из перспективных источников Аи для минерально-сырьевой базы благородных металлов России.

\section{6. БЛАГОДАРНОСТИ}

Авторы благодарны за помощь в аналитических исследованиях сотрудникам ИГХ СО РАН Т.М. Пастушковой (ФХА-ААС) и И.Ю. Вороновой (ААС), а также сотруднику ЛИН СО РАН К.Ю. Арсентьеву (СЭМ-ЭДС).

\section{7. ЗАЯВЛЕННЫЙ ВКЛАД АВТОРОВ / CONTRIВUTION OF THE AUTHORS}

Все авторы внесли эквивалентный вклад в подготовку публикации.

The authors contributed equally to this article.

\section{8. КОНФЛИКТ ИНТЕРЕСОВ / CONFLICT OF INTERESTS}

Авторы заявляют об отсутствии у них конфликта интересов. Все авторы прочитали рукопись и согласны с опубликованной версией.

The authors have no conflicts of interest to declare. All authors have read and agreed to the published version of the manuscript.

\section{9. ЛИТЕРАТУРА / REFERENCES}

Dubosq R., Rogowitz A., Schweinar K., Gault B., Schneider D.A., 2019. A 2D and 3D Nanostructural Study of Naturally Deformed Pyrite: Assessing the Links between Trace Element Mobility and Defect Structures. Contribution to Mineralogy and Petrology 174, 72. https://doi.org/10.10 07/s00410-019-1611-5.

Finkelshtein A.L., Tatarinov V.V., Finkelstein E.A., Pavlova L.A., Kravtsova R.G., 2018. About the Assessment of Gold Concentrations in Tiny Inclusions within Sulfide Mineral Matrix: An Electron Microprobe Study. X-Ray Spectrometry 47 (6), 423-431. https://doi.org/10.1002/xrs.2967.

Firsov L.V., 1985. Gold-Quartz Formation of the YanaKolyma Belt. Nauka, Novosibirsk, 217 p. (in Russian) [Фирсов Л.В. Золото-кварцевая формация Яно-Колымского пояса. Новосибирск: Наука, 1985. 217 с.].

Gold Determination in Rocks, Ores and Their Processed Products by Extraction-Atomic-Absorption Method with Organic Sulfides, 2016. NSAM № 237-S Methods. VIMS, Moscow, 18 p. (in Russian) [Определение золота в горных породах, рудах и продуктах их переработки экстракционно-атомно-абсорбционным методом с органическими сульфидами: Методика НСАМ № 237-С. М.: ВИМС, 2016. 18 с.].

Goncharov V.I., Voroshin S.V., Sidorov V.A., 2002. Natalka Gold Lode Deposit. North East Interdisciplinary Scientific Research Institute FEB RAS, Magadan, 250 p. (in Russian) [Гончаров В.И., Ворошин С.В., Сидоров В.А. Наталкинское золоторудное месторождение. Магадан: СВКНИИ ДВО РАН, 2002. 250 с.].

Goryachev N.A., Vikent'eva O.V., Bortnikov N.S., Prokof'ev V.Yu., Alpatov V.A., Golub V.V., 2008. The World-Class Natalka Gold Deposit, Northeast Russia: REE Patterns, Fluid Inclusions, Stable Oxygen Isotopes, and Formation 
Conditions of Ore. Geology of Ore Deposits 50, 362. https:// doi.org/10.1134/S1075701508050024.

Goryachkin N.I., Chinenov V.A., Khoroshilov V.L., 1999. Mineralogical Characteristics of Gold Lost during Ore Processing at the Natalka Deposit (North-East of Russia). Proceedings of Higher Educational Establishments. Geology and Exploration 5, 95-102 (in Russian) [Горячкин Н.И., Чиненов В.А., Хорошилов В.Л. Минералогические характеристики золота, потерянного при переработке руд на месторождении Наталка (северо-восток России) // Известия высших учебных заведений. Геология и разведка. 1999. № 5. С. 95-102].

Grigorov S.A., Vorozhbenko V.D., Kushnarev P.I., Markevich V.Yu., Tokarev V.N., Chichev V.I., Yagubov N.P., Mikhailov B.K., 2007. Geology and Key Signatures of the Natalkinskoe Gold Deposit. National Geology 3, 43-50 (in Russian) [Григоров С.А., Ворожбенко В.Д., Кушнарев П.И., Маркевич В.Ю., Токарев В.Н., Чичев В.И., Ягубов Н.П., Михайлов Б.К. Наталкинское золоторудное месторождение строение и основные поисковые признаки // Отечественная геология. 2007. № 3. С. 43-50].

Kravtsova R.G., Tauson V.L., Goryachev N.A., Makshakov A.S., Arsent'ev K.Yu., Lipko S.V., 2020a. SEM Study of the Surface of Arsenopyrite and Pyrite from the Natalkinskoe Deposit, Northeastern Russia. Geochemistry International 58, 531-538. https://doi.org/10.1134/S00167029 20050031.

Kravtsova R.G., Tauson V.L., Makshakov A.S., Bryansky N.V., Smagunov N.V., 2020b. Platinum Group Elements in Arsenopyrites and Pyrites of the Natalkinskoe Gold Deposit (Northeastern Russia). Minerals 10 (4), 318. https:// doi.org/10.3390/min10040318.

Kravtsova R.G., Tauson V.L., Nikitenko E.M., 2015. Modes of $\mathrm{Au}, \mathrm{Pt}$, and Pd Occurrence in Arsenopyrite from the Natalkinskoe Deposit, NE Russia. Geochemistry International 53, 964-972. https://doi.org/10.1134/S00167029 15090037.

Mikhailov B.K., Struzhkov S.F., Aristov V.V., Natalenko M.V., Tsymbalyuk N.V., Tyamisov N.E., Uzyunkoyan A.A., 2007. Gold Potential of the Yana-Kolyma Province. Ores and Metals 5, 4-17 (in Russian) [Михайлов Б.К., Стружков С.Ф., Аристов В.В., Наталенко М.В., Цымбалюк Н.В., Тямисов Н.Э., Узюнкоян А.А. Потенциал золотоносности ЯноКолымской провинции // Руды и металлы. 2007. № 5. C. 4-17].
Palymsky B.F., Egorov V.N., Volkov A.V., 2006. Metallogeny of Magadan Oblast' and Prospects for Development of Mineral Raw-Material Base. Proceedings of Higher Educational Establishments. Geology and Exploration 1, 37-42 (in Russian) [Палымский Б.Ф., Егоров В.Н., Волков А.В. Металлогения Магаданской области и перспективы развития минерально-сырьевой базы // Известия высших учебных заведений. Геология и разведка. 2006. № 1. C. 37-42].

Pavlova L.A., 2014. The Electron Probe X-Ray Microanalysis and Its Utilization. Lambert Academic Publishing, Saarbrucken, 294 p.

Pavlova L.A., Belozerova O.Yu., Paradina L.F., Suvorova L.F., 2000. X-Ray Electron Probe Microanalysis of Natural Objects. Nauka, Novosibirsk, 224 p. (in Russian) [Павлова Л.А., Белозерова О.Ю., Парадина Л.Ф., Суворова Л.Ф. Рентгеноспектральный электронно-зондовый микроанализ природных объектов. Новосибирск: Наука, 2000. 224 c.].

Tauson V.L., Bessarabova O.I., Kravtsova R.G., Pastushkova T.M., Smagunov N.V., 2002. Determination of Binding Forms of Gold in Pyrite by Means of Statistical Analysis. Russian Geology and Geophysics 43 (1), 57-67 (in Russian) [Таусон В.Л., Бессарабова О.И., Кравцова Р.Г., Пастушкова Т.М., Смагунов Н.В. О разделении форм нахождения золота в пиритах путем исследования статистических выборок аналитических данных // Геология и геофизика. 2002. Т. 43. № 1. С. 57-67].

Tauson V.L., Kravtsova R.G., Smagunov N.V., Spiridonov A.M., Grebenshchikova V.I., Budyak A.E., 2014. Structurally and Superficially Bound Gold in Pyrite from Deposits of Different Genetic Types. Russian Geology and Geophysics 55 (2), 273-289. https://doi.org/10.1016/j.rgg. 2014.01.011.

Tauson V.L., Lipko S.V., Smagunov N.V., Kravtsova R.G., Arsent'ev K.Yu., 2018. Distribution and Segregation of Trace Elements during the Growth of Ore Mineral Crystals in Hydrothermal Systems: Geochemical and Mineralogical Implications. Russian Geology and Geophysics 59 (12), 17181732. https://doi.org/10.1016/j.rgg.2018.12.013.

Tauson V.L., Lustenberg E.K., 2008. Quantitative Determination of Modes of Gold Occurrence in Minerals by the Statistical Analysis of Analytical Data Samplings. Geochemistry International 46, 423-428. https://doi.org/10.1134/ S0016702908040101. 